\title{
Inter- and intramolecular $\mathrm{CF} \cdots \mathrm{C}=\mathrm{O}$ interactions on aliphatic and cyclohexane carbonyl
} derivatives

Rodrigo A. Cormanich, ${ }^{\mathrm{a}, \mathrm{b}}$ Roberto Rittner ${ }^{\mathrm{b}}$, David O'Hagan and Michael Bühl ${ }^{\mathrm{a}^{*}}$

${ }^{a}$ School of Chemistry, University of St Andrews, North Haugh, St Andrews, Fife KY169ST, UK.

${ }^{b}$ Chemistry Institute, State University of Campinas, P.O. Box 6154, 13083-971, Campinas, SP,

Brazil.

*E-mail: $\underline{\text { mb105@st-andrews.ac.uk }}$

\begin{abstract}
The assessment of weak inter- and intra- molecular $\mathrm{C}^{\delta+} \mathrm{F}^{\delta-} \ldots \mathrm{C}^{\delta+}=\mathrm{O}^{\delta-}$ interactions were theoretically evaluated in 4 different sets of compounds at different theoretical levels. Intermolecular $\mathrm{CH}_{3} \mathrm{~F} \cdots \mathrm{C}=\mathrm{O}$ interactions were stabilizing by ca. $1 \mathrm{kcal} \mathrm{mol}^{-1}$ for various carbonyl containing functional groups. Intramolecular $\mathrm{CF} \cdots \mathrm{C}=\mathrm{O}$ interactions were also detected in aliphatic and fluorinated cyclohexane carbonyl derivatives. However, the stabilisation provided by intramolecular $\mathrm{CF} \cdots \mathrm{C}=\mathrm{O}$ interactions was not enough to govern the conformational preferences of compounds $\mathbf{2 - 4}$.
\end{abstract}

Keywords: organofluorine compounds, stereoelectronic effects, $\mathrm{CF}{ }^{\cdots} \mathrm{C}=\mathrm{O}$ interactions.

In memory of Prof Paul von RagueSchleyer 


\section{Introduction}

Organofluorine compounds have been widely used in medicinal chemistry in order to improve the physicochemical properties of bioactives. ${ }^{[1,2,3]}$ The fluorine atom shows a unique combination of steric and electronic properties: in terms of size it is the next smallest atom after hydrogen that can covalently bond to carbon. ${ }^{[4,5,6]}$ Thus, replacement of $\mathrm{H}$ by $\mathrm{F}$ does not significantly change the shape of the molecule. ${ }^{[7]}$ In fact, several studies have shown that F can successfully act as a $\mathrm{H}$ mimic, and retain good binding to a receptor/enzyme. ${ }^{[8]}$ On the other hand, due to the high eletronegativity of $\mathrm{F}$ in comparison to $\mathrm{H}$ (4.0 and 2.1, respectively, on the Pauling scale $\left.{ }^{[9]}\right)$, the physicochemical properties of a fluorinated medicine can differ significantly from a non-fluorinated one. This can lead to improved ADME (absorption, distribution, metabolism and excretion) characteristics. ${ }^{[10]}$ It follows from the high electronegativity of $\mathrm{F}$ that the $\mathrm{C}^{\delta+}-\mathrm{F}^{\delta-}$ bond is highly polarised. It contains high ionic character, which in turn results in a very strong $\left(\sim 105 \mathrm{kcal} \mathrm{mol}^{-1}\right.$ in average $)$, short and unreactive bond. ${ }^{[1]}$

Moreover, covalently bound fluorine has three lone pairs that are tightly bound to the nucleus. This again follows from the high electronegativity of F. As a consequence, organic bound $\mathrm{F}$ is a poor acceptor in long range interactions, including in hydrogen bonds (HBs). ${ }^{[12]}$ Indeed, although there are an increasing number of examples reported, ${ }^{[13,14]}$ in general the interaction is weak. ${ }^{[15,16,17]}$ Also, the evidence for a multitude of long range interactions involving $\mathrm{F}$, as e.g.: $\mathrm{CF} \cdots \mathrm{FC}, \mathrm{CF} \cdots \pi$-arene and $\mathrm{CF} \cdots \mathrm{HC}$ is contested largely because the interactions are very weak and hard to measure or model with confidence. ${ }^{[18,19]}$ Thus, when a $\mathrm{H}$ atom is replaced by a $\mathrm{F}$ atom in a drug, the occurrence and impact of long range interactions is difficult to anticipate, hampering the development of new medicinal compounds. In this regard, we have studied CF...FC interactions in several organic compounds. In some cases these interactions appear to be stabilising and in others destabilising depending on the molecular systems investigated and the methods employed. ${ }^{[20]}$ 
Another potentially interesting long-range interaction is that between an electron-rich organic $\mathrm{F}$ atom and the electrophilic $\mathrm{C}$ atom of a carbonyl/carboxyl group. ${ }^{21}$

Such interactions can clearly be very important in a pharmacological context, eg. where the amide carbonyls of a peptide backbone of a protein or receptor can interact with a fluorinated ligand/drug. There is indeed good evidence to support a role for $\mathrm{CF} \cdots \mathrm{C}=\mathrm{O}$ interactions in protein-drug interaction, based on an analysis of close non-covalent contacts in the Cambridge Structural Database ${ }^{[22]}$ and the Protein Data Bank. ${ }^{[23,[24,25,26,27]}$ Thus, as part of a programme to understand long range interactions involving $\mathrm{F}$ atoms in organic compounds, we have studied, using theoretical calculations at different DFT and ab initio theoretical levels, $\mathrm{C}^{\delta+} \mathrm{F}^{\delta-} \ldots \mathrm{C}^{\delta+} \mathrm{O}^{\delta-}$ interactions in different aliphatic and cyclic organofluorine compounds containing a variety of carbonyl functionalities.

\section{Computational details}

Geometry optimisations were performed using the Gaussian09 program, Revision D.01, ${ }^{[28]}$ at the B3LYP, ${ }^{[29,30]}$ B3LYP-D3 ${ }^{[31]}$ and MP2 theoretical levels employing aug-cc-pVDZ basis set. For the intermolecular complexes $\mathbf{1}$ optimisations included a correction for basis set superposition errors through the counterpoise method, ${ }^{[32,33]}$ and were carried out imposing the following constraints: $\mathrm{C}-\mathrm{F} \ldots \mathrm{C}(\mathrm{O})$ and $\mathrm{F} \ldots \mathrm{C}=\mathrm{O}$ angles for all these dimers were fixed to $177.0^{\circ}$ and to $89.5^{\circ}$, respectively. Mulliken, NPA (Natural Population Analysis) and CHelpG (Charges from Electrostatic Potentials using a Grid based method) atomic charges were computed for these optimised structures using Gaussian09 program, and QTAIM charges were computed using AIMALL. ${ }^{34}$ Molecules in sets 2-4 were fully optimised at the given theoretical levels, and minima were characterised through computation of the harmonic vibrational frequencies, which were also used to evaluate thermodynamic corrections affording enthapies and Gibbs free energies at ambient, standard temperature and pressure. Spin-spin coupling constants (SSCCs) were also computed with Gaussian09 at the BHandH/EPR-III theoretical level; ${ }^{[35,36]}$ this and related theoretical levels have performed very well in the computation of a very large variety of 
spin-spin coupling constants (SSCCs) involving carbon, fluorine and hydrogen atoms ${ }^{[37]}$; the EPR-III basis set has also been optimised for the computation of the Fermi-contact component of SSCCs. ${ }^{[38]}$ Conformers were found by using B3LYP/cc-pVDZ Monte Carlo conformational searches with the Spartan 14 program, ${ }^{[39]}$ using a $10 \mathrm{kcal} \mathrm{mol}^{-1}$ threshold and $5000 \mathrm{~K}$ temperature initial temperature in the simulated-annealing algorithm. NBO analysis ${ }^{40}$ was performed at the B3LYP-D3/aug-cc-pVDZ theoretical level employing geometries fully optimised at the same theoretical level. NCI calculations were also performed on the obtained B3LYP-D3/aug-cc-pVDZ electron densities by using the NCIPLOT 3.0 program. ${ }^{[41]}$

\section{Results and discussion}

Four sets of molecular systems were selected for study (Scheme 1). The set of structures $\mathbf{1}$ may form intermolecular $\mathrm{CF} \cdots \mathrm{C}=\mathrm{O}$ interactions, $\mathbf{2}$ is a set of cyclohexane derivatives which may form 5-membered rings upon formation of intramolecular $\mathrm{CF} \cdots \mathrm{C}=\mathrm{O}$ interactions and $\mathbf{3}$ and 4 were chosen as a set of the simplest aliphatic which may form 5- and 6-membered rings upon formation of intramolecular $\mathrm{CF} \cdots \mathrm{C}=\mathrm{O}$ interactions.
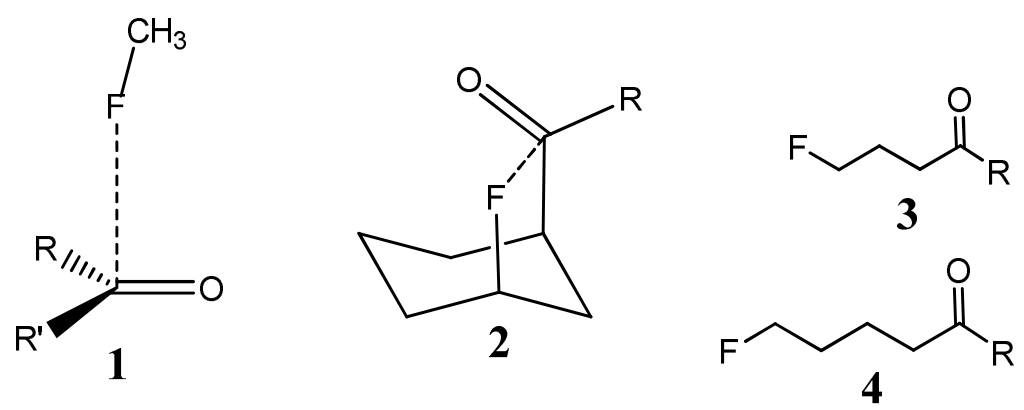

$$
\begin{aligned}
& \text { a } R, R^{\prime}=H \\
& \text { b } R=H, R^{\prime}=M e \\
& \text { c } R, R^{\prime}=M e \\
& \text { d } R=M e, R^{\prime}=O M e \\
& \text { e } R=M e, R^{\prime}=\mathrm{NHMe} \\
& \text { f } R=M e, R^{\prime}=\mathrm{NMe}_{2} \\
& \text { g } R=M e, R^{\prime}=\mathrm{Cl} \\
& \text { h } R=M e, R^{\prime}=F \\
& \text { i } R, R^{\prime}=F \\
& \text { j } R, R^{\prime}=\mathrm{CF}_{3} .
\end{aligned}
$$

a $\mathrm{R}=\mathrm{H}$

b $\mathrm{R}=\mathrm{Me}$

c $\mathrm{R}=\mathrm{OMe}$

a $\mathrm{R}=\mathrm{H}$

d $\mathrm{R}=\mathrm{NHMe}$

b $\mathrm{R}=\mathrm{Me}$

c $\mathrm{R}=\mathrm{OMe}$

e $\mathrm{R}=\mathrm{NMe}_{2}$

d R $=\mathrm{NMe}_{2}$

f $\mathrm{R}=\mathrm{Cl}$

e $\mathrm{R}=\mathrm{Cl}$

f $\mathrm{R}=\mathrm{F}$

g R $=\mathrm{F}$

h $\mathrm{R}=\mathrm{CF}_{3}$.

$\mathbf{g} \mathrm{R}=\mathrm{CF}_{3}$. 
Scheme 1: Representations of the structures chosen for this study.

The interaction between fluoromethane and formaldehyde can be considered the simplest model for the intermolecular $C F \cdots C=O$ interaction $\left(R, R^{\prime}=H\right.$; compound 1a). When this complex is fully optimised without constraints, the structure shown in Figure 1a is obtained. Apparently, this energy minimum enjoys additional stabilisation from a $\mathrm{CH} \cdots \mathrm{O}$ interaction (distance $2.53 \AA$ at the B3LYP-D3/aug-cc-pVDZ theoretical level), which causes the methyl group to bend toward the carbonyl oxygen. It is known from structure searches in the Cambridge Structure Database that compounds with a $\mathrm{CF} \cdots \mathrm{C}=\mathrm{O}$ interaction tend to adopt conformations where the $\mathrm{F}$ atom is close to the pseudotrigonal axis of the carbonyl $\mathrm{C}$ atom (i.e. with $\mathrm{F} \cdots \mathrm{C}=\mathrm{O}$ angles close to $90^{\circ}$ ) and with $\mathrm{C}-\mathrm{F} \cdots \mathrm{C}$ angles between ca. $120^{\circ}$ and $160^{\circ}$, and occasionally approaching $180^{\circ} \cdot{ }^{[24]}$ In order to better model these observed structures and to describe a predominant $\mathrm{CF} \cdots \mathrm{C}=\mathrm{O}$ interaction unperturbed by other intermolecular interactions, we reoptimised compound 1a with additional constraints that prevent the formation of other interactions (see Computational Details ${ }^{[42]}$ ). The resulting partially optimised structure (which is $2.37 \mathrm{kcal} \mathrm{mol}^{-1}$ above the fully optimised minimum at the B3LYP-D3/aug-cc-pVDZ theoretical level) is shown in Figure 1b.

To probe for the extent of the $\mathrm{CF} \cdots \mathrm{C}=\mathrm{O}$ interaction we constructed binding energy potential curves (BEPCs) by using the F...C distance as an additional constraint. The resulting curves obtained at different theoretical levels are shown in Figure 1c. At all theoretical levels there is an attractive interaction between the $\mathrm{CH}_{3} \mathrm{~F} \cdots \mathrm{C}=\mathrm{O}$ moieties. The curve calculated at the B3LYP/aug-cc-pVDZ theoretical level shows a considerably weaker and longer $\mathrm{CF} \cdots \mathrm{C}=\mathrm{O}$ interaction $\left(-0.37 \mathrm{kcal} \mathrm{mol}^{-1} ; 3.25 \AA\right)$ in the most stable geometry than the found by ab initio MP2 and the dispersion corrected B3LYP-D3 functional (ca. -1.0 kcal mol ${ }^{-1} ; 3.0 \AA$ A), indicating that dispersion effects are important to measure the binding energy of the $\mathrm{CF} \cdots \mathrm{C}=\mathrm{O}$ interaction in this complex. B3LYP-D3 and MP2 results with either aug-cc-pVDZ and aug-cc-pVTZ basis 
sets are equivalent, also showing an interaction energy of ca. $-1.0 \mathrm{kcal} \mathrm{mol}^{-1}$ at the equilibrium geometry. Accordingly, the non-covalent interactions (NCI) method indicated a weak attractive interaction for compound 1a (Figure S1 in the ESI).

According to second-order perturbation analysis of donor and acceptor NBOs, the largest fraction of this interaction stems from donation of the sp-type lone pair on $\mathrm{F}$ into the antibonding $\pi^{*}(\mathrm{C}=\mathrm{O})$ orbital, which has its largest coefficient on the $\mathrm{C}$ atom (see plot in Figure S2 in the ESI).

a)

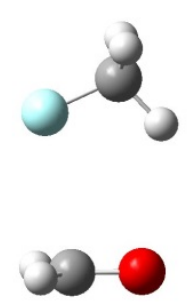

b)

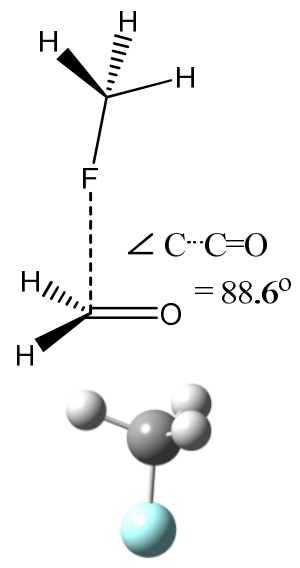

c)

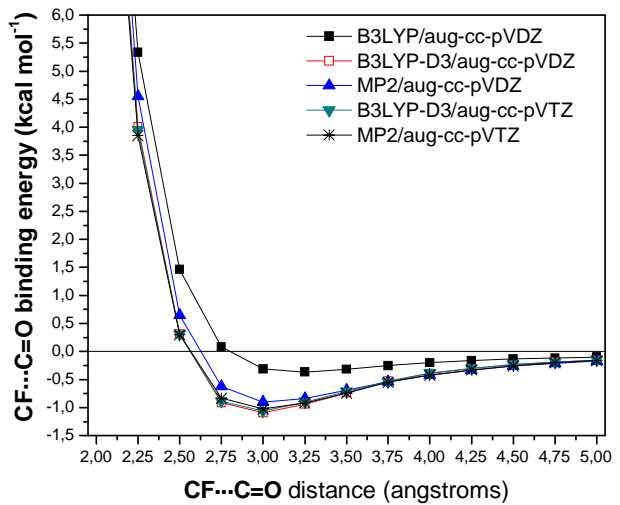

Figure 1: The interaction of methylfluoride with formaldehyde 1a obtained at the B3LYPD3/aug-cc-pVDZ theoretical level: Graphical representations of the MP2 equilibrium geometry (a) and the partially optimised geometry using constraints (b); $\mathrm{CF}^{\cdots} \mathrm{C}^{\cdots} \mathrm{O}$ potential energy curves calculated at different theoretical levels for the constrained structure using the F $\cdots \mathrm{C}$ distance as an additional constraint (c). BSSE corrections included for all cases.

Such an interaction energy may change depending on the substituent $(\mathrm{R})$ attached to the $\mathrm{C}=\mathrm{O}$ group. Also, the $\mathrm{CH}_{3} \mathrm{~F} \cdots \mathrm{C}=\mathrm{O}$ angle of approach may change depending on the volume of the $\mathrm{R}$ groups. In order to evaluate the steric perturbation caused by more voluminous $\mathrm{R}$ groups, we studied acetaldehyde $\mathbf{1 b}\left(\mathrm{R}=\mathrm{H} ; \mathrm{R}^{\prime}=\mathrm{CH}_{3}\right)$ and acetone $\mathbf{1 c}\left(\mathrm{R}=\mathrm{R}^{\prime}=\mathrm{CH}_{3}\right)$ see Figures $2 \mathrm{a}$ and $2 \mathrm{~b}$, respectively. The $\angle \mathrm{C}{ }^{\cdots} \mathrm{C}=\mathrm{O}$ angle in the acetaldehyde $\mathbf{1 b}\left(102.4^{\circ}\right)$ complex does not seem 
to be affected much by the additional $\mathrm{CH}_{3}$ group relative to formaldehyde 1a. In contrast, the Me groups of acetone 1c seem to repel the $\mathrm{CH}_{3} \mathrm{~F}$ group considerably, resulting in a bended $\angle$ $\mathrm{C}^{\cdots} \mathrm{C}=\mathrm{O}$ of $80.7^{\circ}$. The BEPCs calculated at the B3LYP/aug-cc-pVDZ theoretical level are not in agreement with those calculated at the B3LYP-D3/aug-cc-pVDZ and MP2/aug-cc-pVDZ theoretical levels (Figures 2e and 2f). The B3LYP functional affords an interaction energy in acetaldehyde $\mathbf{1 b}$ of only $-0.1 \mathrm{kcal} \mathrm{mol}^{-1}$, while B3LYP-D3 and MP2 agree that it is ca. $-1.0 \mathrm{kcal}$ $\mathrm{mol}^{-1}$. Also B3LYP indicates that the $\mathrm{CF} \cdots \mathrm{C}=\mathrm{O}$ interaction in acetone $\mathbf{1 c}$ is repulsive, while MP2 and B3LYP-D3 indicate that it is rather attractive by -1.3 and $-1.9 \mathrm{kcal} \mathrm{mol}^{-1}$, respectively. Apparently, this slight increase in attraction for $\mathbf{1 c}$ compared to $\mathbf{1 a}$ and $\mathbf{1 b}$ is related to the stronger dispersion in the more bulky derivative 1c. Despite the absence of direct BSSE and dispersion corrections in the electron density (these effects are only included indirectly via optimisation), the NCI method also predicts a weakly attractive interaction for 1c (result not shown).

a)

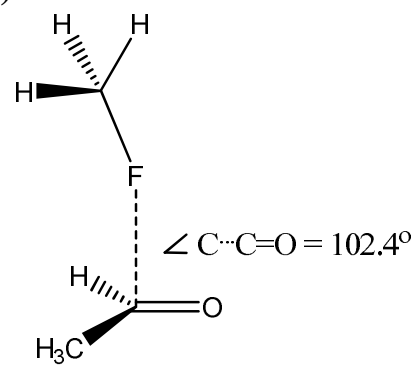

b)

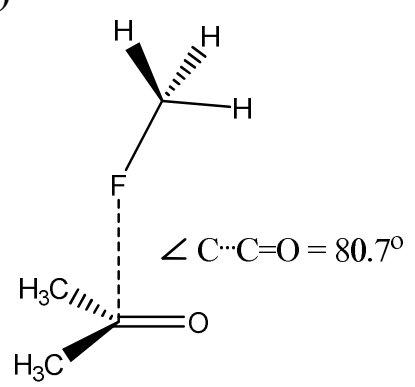

c)

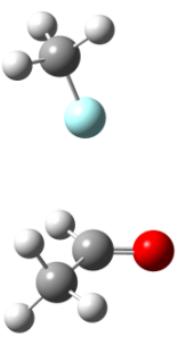

d)

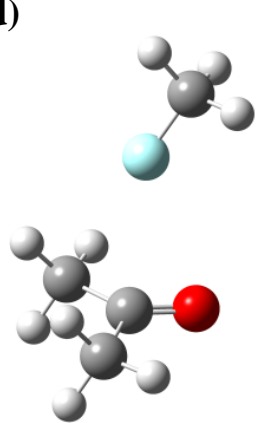

e)

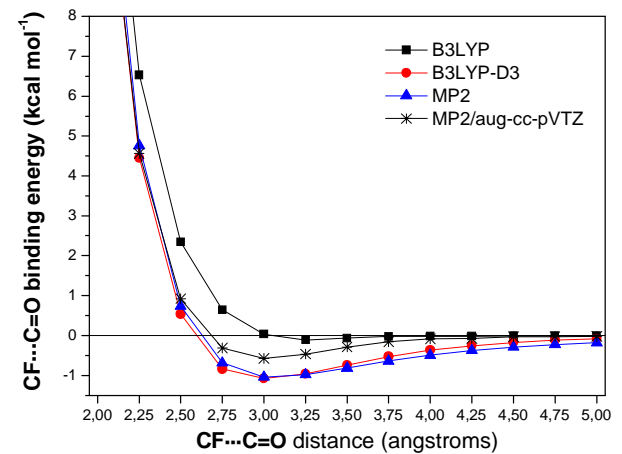

f)

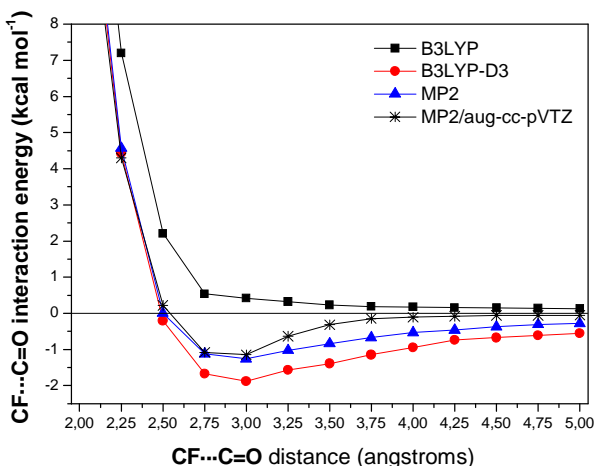

Figure 2: Graphical representations (a-d) of complexes of methylfluoride with acetaldehyde 1b and acetone 1c obtained at the B3LYP-D3/aug-cc-pVDZ level and $C F{ }^{\cdots} \mathrm{C}=\mathrm{O}$ BEPC (e-f) 
calculated at the B3LYP, B3LYP-D3 and MP2 methods using the aug-cc-pVDZ basis set. MP2/aug-cc-pVTZ single points on MP2/aug-cc-pVDZ geometries are also shown. BSSE corrections are included for all cases.

In order to explore the interaction energy dependence on the carbonyl substrate, we expanded the molecular set to the corresponding ester, amide, acyl chloride and fluorinated derivatives (compounds 1d-1j). The BEPCs obtained at different theoretical levels for all these compounds are shown in the ESI (Figures S3-S9) together with their geometric representations (for schematic representations see Scheme 2). Again, B3LYP without dispersion corrections severely underestimates the $\mathrm{CF} \cdots \mathrm{C}=\mathrm{O}$ interactions (compared to MP2 and B3LYP-D3) and fails to detect them in compounds 1d-1f. The MP2 and B3LYP-D3 data are remarkably close to each other throughout. Thus, we will only discuss the B3LYP-D3/aug-cc-pVDZ results from now on and use that theoretical level to study the $\mathrm{CF} \cdots \mathrm{C}=\mathrm{O}$ interactions in the compounds $\mathbf{2 - 4}$.

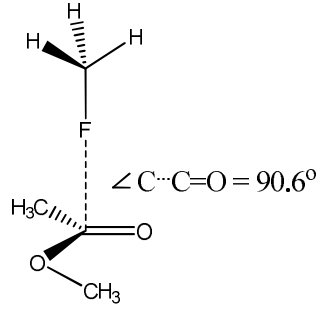

1d

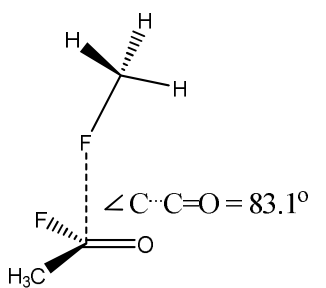

$1 \mathrm{~h}$

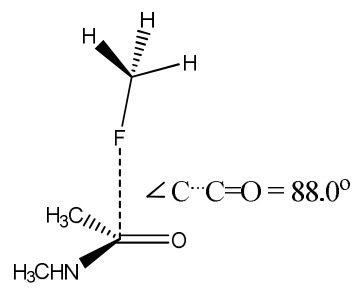

1e

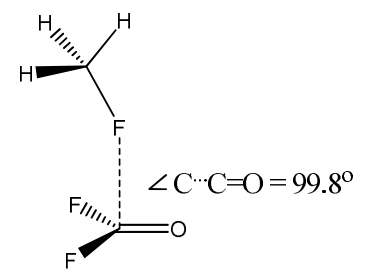

$1 \mathbf{i}$

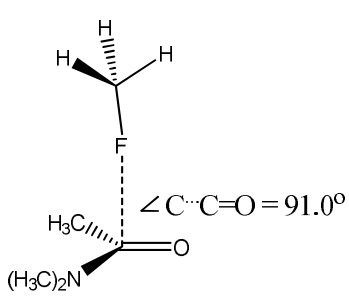

1f

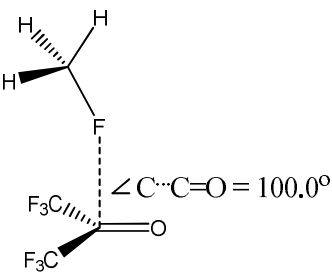

$\mathbf{1 j}$

Scheme 2: Geometric representations of complexes between methyl fluoride and carbonyl compounds $\mathbf{1 d}-\mathbf{1 j}$, including $\mathrm{C} \cdots \mathrm{C}=\mathrm{O}$ angles obtained from B3LYP-D3/aug-cc-pVDZ constrained optimisations. BSSE corrections included for all cases. 
Figure 3 shows the BEPCs for fluoromethyl complexes with compounds $\mathbf{1 d}-\mathbf{1 j}$ at the B3LYP-D3/aug-cc-pVDZ theoretical level (MP2/aug-cc-pVTZ single point BEPCs may be found in the ESI). The methyl acetate ester (1d) together with $\mathrm{N}$-methyl and $\mathrm{N}, \mathrm{N}$-dimethyl acetamide derivatives 1e and $\mathbf{1 f}$ form the weakest $\mathrm{CF} \cdots \mathrm{C}=\mathrm{O}$ interactions (ca. $-1.0 \mathrm{kcal} \mathrm{mol}^{-1}$ ). This result is interesting, because 1e is a minimal model for the peptide bonds in protein chains. It appears from this analysis that it is not the $\mathrm{CF} \cdots \mathrm{C}=\mathrm{O}$ interaction that is primarily responsible for the "fluorophilic environment" provided by the amide bonds in proteins, but that other interactions (such as $\mathrm{CF} \cdots \mathrm{HC}-\mathrm{C}=\mathrm{O}^{\alpha}$ hydrogen bonds) may be of greater significance.. ${ }^{24}$

Interestingly, when more electronegative groups as $\mathrm{Cl}, \mathrm{F}$ and $\mathrm{CF}_{3}$ are directly attached to the $\mathrm{C}=\mathrm{O}$ group, the interaction energy increases considerably, namely to $-1.8 \mathrm{kcal} \mathrm{mol}^{-1}$ for compounds $\mathbf{1 g}$ and $\mathbf{1 h},-2.4 \mathrm{kcal} \mathrm{mol}^{-1}$ for $\mathbf{1 i}$ and $-4.5 \mathrm{kcal} \mathrm{mol}^{-1}$ for $\mathbf{1 j}$ (Figure 3). However, the largest interaction energy found for hexafluoroacetone $\mathbf{1 j}$ may have contributions from $\mathrm{CF} \cdots \mathrm{H}-$ $\mathrm{C}$ hydrogen bonds between the fluoromethyl groups of $\mathbf{1} \mathbf{j}$ and the methyl hydrogens of

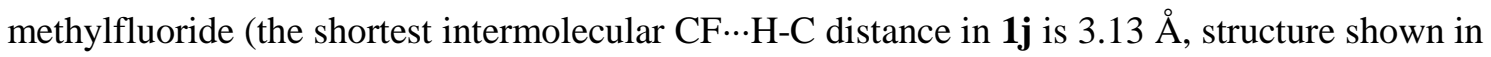
Figure S9). Because the $\mathrm{CF} \cdots \mathrm{C}=\mathrm{O}$ interaction in the complexes $\mathbf{1 a - 1 \mathbf { j }}$ is weak and apparently rather multi-faceted (electrostatics, dispersion, and also some charge transfer according to second-order perturbation analysis of the NBOs) it is difficult to single out one factor that would determine the interaction energies. For instance there are no apparent correlations with simple descriptors such as atomic charges (see e.g. the charges on carbon in ESI Table S1) or $\mathrm{C}=\mathrm{O}$ stretching frequencies. 


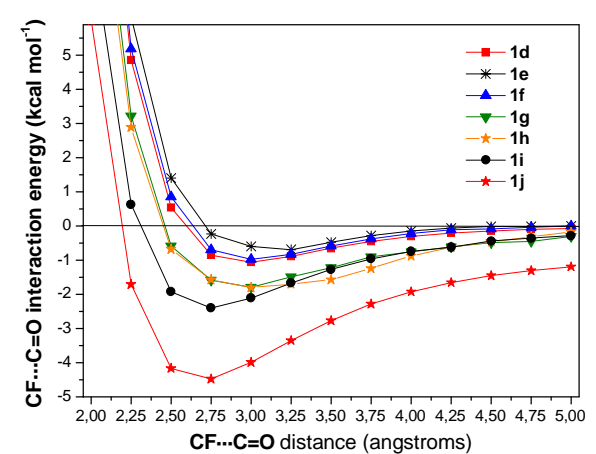

Figure 3: BEPC for compounds 1d-1j obtained at the B3LYP-D3/aug-cc-pVDZ theoretical level. BSSE corrections included for all cases.

In order to probe to what extent the $\mathrm{CF} \cdots \mathrm{C}=\mathrm{O}$ interaction might manifest itself in observable NMR properties, we evaluated the $J(\mathrm{~F}, \mathrm{C})$ spin-spin coupling constants (SSCCs) for each complex. Weak through-space or through-(hydrogen) bond interactions can often be detected through similar $J_{\mathrm{FH}}$ couplings. ${ }^{[43]}$ The graphs of $J(\mathrm{~F}, \mathrm{C})$ vs the CF...CO distance are shown in Figure 4. The SSCCs values are transferred "through-space" $\left[{ }^{\mathrm{TS}} J(\mathrm{~F}, \mathrm{C})\right]$ and increase with decreasing $\mathrm{CF} \cdots \mathrm{CO}$ distance. The total $J(\mathrm{~F}, \mathrm{C})$ values were decomposed into the Ramsey FC (Fermi Contact), SD (Spin dipolar), PSO (Paramagnetic Spin-orbit) and DSO (Diamagnetic Spin-Orbit) contributions. As Figure 4 shows, all compounds $J(\mathrm{~F}, \mathrm{C})$ values are dominated by the FC term. Interestingly the $J(\mathrm{~F}, \mathrm{C})$ values are positive for compounds $\mathbf{1 a - 1 g}$, but negative for the fluorinated derivatives $\mathbf{1 h}-\mathbf{1} \mathbf{j}$. For most species, the predicted $J(\mathrm{~F}, \mathrm{C})$ values near the minima in the respective BEPCs (ca. $3 \AA$, cf. Figures 1 - 3) amount to ca. $\pm 2 \mathrm{~Hz}$. For the F-, and $\mathrm{CF}_{3^{-}}$ species $\mathbf{1} \mathbf{i}$ and $\mathbf{1} \mathbf{j}$ with their minimum energy distances around $2.75 \AA$ (Figure 3 ), $J(\mathrm{~F}, \mathrm{C}$ ) couplings around $-3 \mathrm{~Hz}$ are obtained. These values are thus small, but might be detectable in favorable cases. The small magnitude is not unexpected, given that the $\mathrm{CF} \cdots \mathrm{C}=\mathrm{O}$ interaction is weak and mostly involves orbitals with little $s$-character on carbon (cf. the NBO analysis discussed above). 


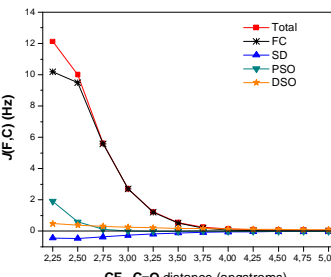

$1 \mathbf{a}$

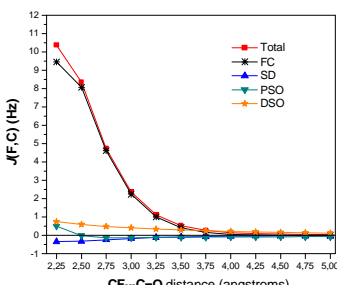

1e

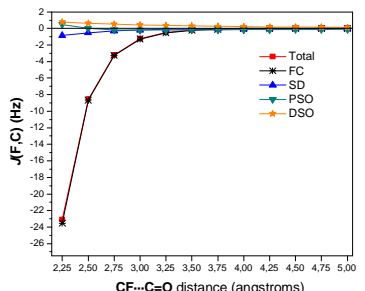

1i

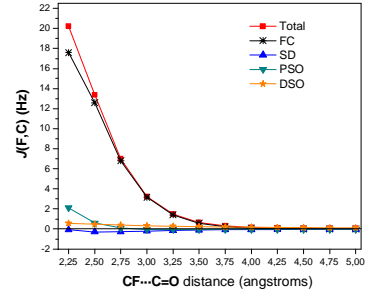

$1 \mathbf{b}$

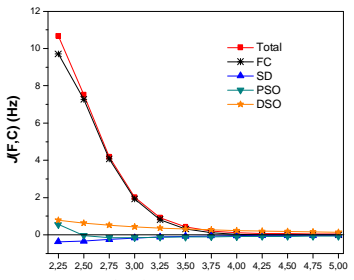

1f

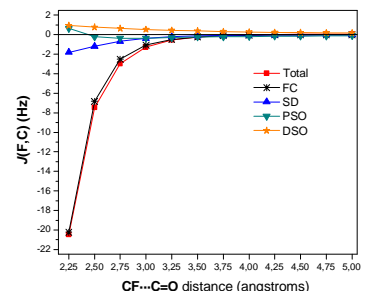

$\mathbf{1 j}$

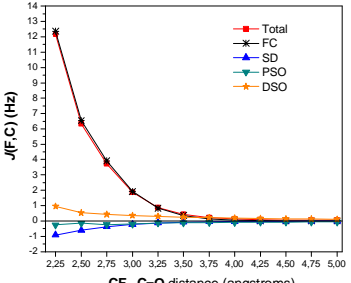

$1 c$

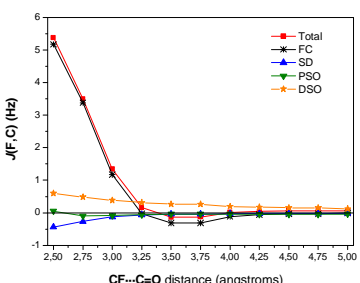

$1 \mathrm{~g}$

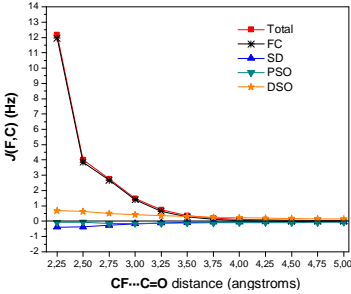

$1 d$

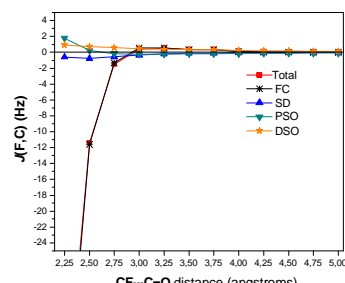

$1 \mathrm{~h}$

Figure 4: Complexes of methylfluoride with $\mathbf{1 a}-\mathbf{1 j} J(\mathrm{~F}, \mathrm{C}) \mathrm{SSCC}$ values $(\mathrm{Hz})$ vs $\mathrm{CF} \cdots \mathrm{C}=\mathrm{O}$ distance $(\AA)$ ) calculated at the BHandH/EPR-III theoretical level on B3LYP-D3/aug-cc-pVDZ optimised geometries.

Thus, it appears that $\mathrm{CF} \cdots \mathrm{C}=\mathrm{O}$ interactions may amount to stabilization of ca. $1 \mathrm{kcal} \mathrm{mol}^{-1}$ in common organic functional groups such as aldehydes, ketones, esters and amides, but that they may not be a particularly good pathway for transmission of $J(\mathrm{~F}, \mathrm{C})$ SSCCs. In order to evaluate if such CF...CO interactions may form an intramolecular interaction, and to what extent such an interaction might influence the ground state conformational preferences, we have studied the cis 1,3-cyclohexane derivatives $\mathbf{2}$ with the corresponding functional groups attached to the carbonyl that were explored for complexes $\mathbf{1}$. CF $\cdots \mathrm{C}=\mathrm{O}$ interactions could occur in the conformers where both $\mathrm{F}$ and $\mathrm{C}(\mathrm{O}) \mathrm{R}$ substituents are in axial orientations (cf. structural representations of $\mathbf{2 a - 2 h}$ in Scheme 3). We were interested whether some of these conformers could be stabilised and, thus, populated (in addition to the intrinsically more stable bis-equatorial conformers) to such an extent that they would be detectable by NMR. Optimal conformations of the $\mathrm{C}(\mathrm{O}) \mathrm{R}$ groups in both the diaxial and diequatorial conformations of the 1,3-cyclohexanes were found by 
constructing potential energy curves (PECs) at the B3LYP-D3/cc-pVDZ for each (Figures S10S17 in the ESI).

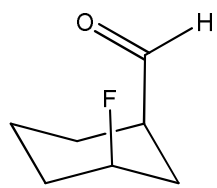

$2 \mathbf{a}$

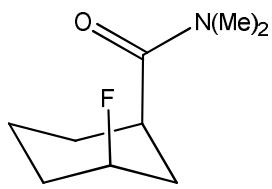

$2 e$

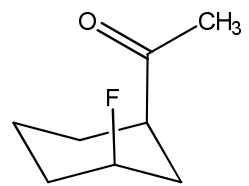

2b

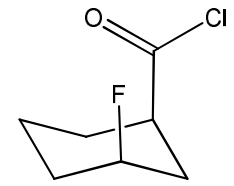

2f

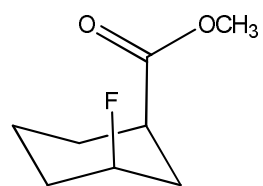

2c

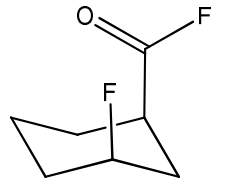

$2 \mathrm{~g}$

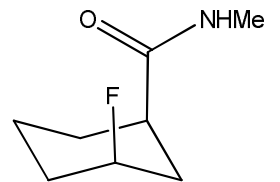

2d

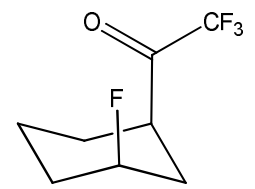

2h

Scheme 3: Diaxial representations of compounds $\mathbf{2 a - 2 h}$.

Each compound showed two axial and two to three equatorial conformers, which were subsequently optimised at the B3LYP/aug-cc-pVDZ, B3LYP-D3/aug-cc-pVDZ and MP2/augcc-pVDZ theoretical levels. MP2/aug-cc-pVTZ//MP2/aug-cc-pVDZ single point calculations were also obtained for comparison (Tables S2-S9 in the ESI). In line with the findings for complexes 1, only the B3LYP-D3 results are discussed (for compounds $\mathbf{2}$, optimisations could not be corrected for intramolecular BSSE; ${ }^{[44]}$ because correlated wavefunction-based methods tend to suffer more from BSSE than DFT, MP2/aug-cc-pVDZ gave smaller CF $\cdots \mathrm{C}=\mathrm{O}$ distances and lower energies for the axial comformers than B3LYP-D3/aug-cc-pVDZ). As expected, the diequatorial conformers emerged as the global minima, although some of the diaxial conformers are close in energy. For compounds $\mathbf{2 a}, \mathbf{2 b}$ and $\mathbf{2 g}$, the diaxial conformers are only $0.3 \mathrm{kcal} / \mathrm{mol}^{-}$ ${ }^{1}$ less stable (see $\Delta E$ values in Tables S2-S8). These energy differences would translate into populations of the diaxial conformers of around 30\% at room temperature [see $\% \mathrm{P}(\Delta E)$ values in Table 1]. However, Gibbs free energies, obtained using standard thermodynamic corrections from frequency calculations, indicate significantly lower populations of axial conformers, ca. 
$20 \%$ or less for $\mathbf{2 a}$ and $\mathbf{2 g}$ (see $\% \mathrm{P}(\Delta G)$ values in Table 1). In this way, the inclusion of entropy effects favours the more flexible extended equatorial conformers.

Table 1: B3LYP-D3/aug-cc-pVDZ calculated relative conformer populations from potential energies, $\% \mathrm{P}(\Delta E)$, relative populations from Gibbs free energies $[\% \mathrm{P}(\Delta \boldsymbol{G}]$, and $J(\mathrm{~F}, \mathrm{C}) \mathrm{SSCCs}$ (Hz, BHandH/EPR-III) for conformers $\mathbf{2 a - 2 h}$.

\begin{tabular}{|c|c|c|c|c|c|c|c|c|c|}
\hline & & $2 a$ & $2 b$ & $2 c$ & $2 d$ & $2 e$ & $2 f$ & $2 g$ & $2 \mathrm{~h}$ \\
\hline \multirow{5}{*}{$\% \mathrm{P}(\Delta E)$} & $a x-1$ & 36.0 & 27.0 & 20.9 & 0.7 & 1.4 & 0.6 & 30.5 & 11.5 \\
\hline & $a x-2$ & 2.2 & 0.5 & 4.0 & $32.8^{a}$ & 0.0 & 17.5 & 2.0 & 0.7 \\
\hline & $e q-1$ & 20.2 & 12.0 & 21.4 & 14.6 & 0.3 & 24.7 & 18.8 & 4.4 \\
\hline & $e q-2$ & 41.6 & 27.4 & 53.7 & 52.0 & 98.3 & 57.2 & 48.7 & 33.4 \\
\hline & $e q-3$ & --- & 33.2 & --- & --- & --- & --- & --- & 50.1 \\
\hline \multirow{5}{*}{$\% \mathrm{P}(\Delta G)$} & $a x-1$ & 22.5 & 5.6 & 5.5 & 0.2 & 0.5 & 0.6 & 14.0 & 4.2 \\
\hline & $a x-2$ & 2.5 & 0.2 & 1.1 & $3.9^{a}$ & 0.0 & 9.7 & 1.6 & 0.1 \\
\hline & $e q-1$ & 26.9 & 11.1 & 25.1 & 11.7 & 0.5 & 23.8 & 21.4 & 2.6 \\
\hline & $e q-2$ & 48.1 & 38.1 & 68.2 & 84.3 & 99.0 & 65.9 & 63.0 & 31.0 \\
\hline & $e q-3$ & --- & 44.9 & --- & --- & --- & --- & --- & 62.1 \\
\hline \multirow{5}{*}{$J(\mathrm{~F}, \mathrm{C})$} & $a x-1$ & 0.10 & -0.37 & -0.48 & -0.01 & -0.49 & -1.04 & -0.99 & -1.62 \\
\hline & $a x-2$ & 0.48 & -0.85 & -0.56 & $0.89^{a}$ & 0.33 & -0.87 & -1.21 & -0.75 \\
\hline & $e q-1$ & 1.02 & 1.61 & 1.76 & 2.13 & 2.05 & 1.99 & 1.74 & 1.83 \\
\hline & $e q-2$ & 1.65 & 1.53 & 1.59 & 1.38 & 1.54 & 1.96 & 1.76 & 1.64 \\
\hline & $e q-3$ & --- & 0.94 & --- & --- & --- & --- & --- & 0.99 \\
\hline
\end{tabular}

${ }^{a} \mathrm{No}$ CF $\cdots \mathrm{C}=\mathrm{O}$ interaction (NH $\cdots \mathrm{FC}$ hydrogen bond).

The CF...CO distance in the diaxial conformers for compounds $\mathbf{2 a - 2 h}$ are in the range of 2.90-3.0 $\AA$, similar to that observed for intermolecular complexes of compounds $\mathbf{1 a - 1 \mathbf { j }}$ with methylfluoride; Figures 1 and 3. It follows that such an interaction should provide $\sim 1 \mathrm{kcal} \mathrm{mol}^{-1}$ of stability, however this is insufficient for the diaxial to dominate the diequatorial conformer. ${ }^{[45]}$ Even for the $\mathrm{CF}_{3}$ derivative $\mathbf{2 h}$, which has the strongest intermolecular $\mathrm{CF} \cdots \mathrm{C}=\mathrm{O}$ interaction energy in model complex $\mathbf{1 j}$ (Figure 3), no such conformational switch is predicted in the corresponding cyclohexane $\mathbf{2 h}$.

The ax-2 conformer of compound $\mathbf{2 d}$ is special, because it possesses a CF $\cdots \mathrm{HN}$ intramolecular hydrogen bond (see structure in Table S5). This structure is $2.3 \mathrm{kcal} / \mathrm{mol}^{-1}$ lower in energy than the $a x-1$ conformer, which has a $\mathrm{CF} \cdots \mathrm{C}=\mathrm{O}$ interaction, but it is still higher than the diequatorial global minimum eq-2 (Table 1). 
The calculated $J_{\mathrm{FC}}$ SSCCs for compounds $\mathbf{2 a - 2 h}$ (Table 1) are in agreement with those in the intermolecular complexes 1a-1j (Figure 4). The calculated $J_{\mathrm{FC}} \mathrm{SSCC}$ values are small and, hence, could not be used as a "direct probe" to detect formation of CF..CO interactions in the cyclohexane derivatives. In fact, the regular ${ }^{4} J(\mathrm{C}, \mathrm{F})$ through-bond couplings in the equatorial conformers are larger than those in the axial species, due to the "W" arrangement of the bonds that are involved, which facilitates transmission of the FC part. ${ }^{[46,47]}$

Compounds 2a-2h may form CF...CO interactions involving 5-membered rings, which, as just discussed, do not provide sufficient conformational stabilisation to favour the diaxial conformers. In order to look for 5-membered rings of formation of CF...CO interactions in a larger set of compounds, we investigated the conformational preferences of the aliphatic fluorinated carbonyl derivatives $\mathbf{3 a - 3 g}$ (Scheme 1). As these compounds have an increased conformational freedom, we used a Monte Carlo conformational search in order to find their conformers (geometric representations of the conformers that have been found for each compound are depicted in Figures S18-S24 in the ESI).

Compounds 3a-3g have between 8 and 14 conformers and their relative populations from Gibbs free energies are given in Table 2 (relative energies, enthalpies and Gibbs free energies are given in Tables S10-S16 in the ESI). Conformers 3x-1 and 3x-2 for each compound are the most stable and together account for ca. $50 \%$ to $90 \%$ of the total population of $\mathbf{3 a - 3 g}$. Conformers that have a geometry that can accommodate a $\mathrm{CF} \cdots \mathrm{C}=\mathrm{O}$ interaction are marked with an asterisk in Table 2. In the event it emerged that such conformers contribute to very low populations (1.8\% or less) and may be considered of little importance in determining the conformational preferences of $\mathbf{3 a - 3 g}$. 
Table 2: Calculated populations of conformers of compounds 3a-3g obtained at the B3LYPD3/aug-cc-pVDZ theoretical level. Populations shown refer to Gibbs free energies $\Delta G$.

\begin{tabular}{cccccccc}
\hline & 3a & 3b & 3c & 3d & 3e & 3f & 3g \\
\hline $\mathbf{3 x - 1}$ & 37.7 & 49.9 & 27.7 & 49.3 & 35.9 & 39.9 & 47.6 \\
$\mathbf{3 x}-\mathbf{2}$ & 33.4 & 39.1 & 21.9 & 10.2 & 31.2 & 31.2 & 42.1 \\
$\mathbf{3 x - 3}$ & 5.5 & $1.7^{*}$ & $1.2^{*}$ & 18.9 & 5.7 & $0.7^{*}$ & $1.5^{*}$ \\
$\mathbf{3 x - 4}$ & $1.8^{*}$ & 5.8 & 5.5 & 5.6 & 6.1 & 4.7 & 0.9 \\
$\mathbf{3 x}-\mathbf{5}$ & 5.4 & 1.6 & $0.7^{*}$ & 9.6 & 4.3 & 5.0 & 4.3 \\
$\mathbf{3 x - 6}$ & 5.0 & $0.5^{*}$ & 3.9 & 1.4 & 4.0 & 4.9 & $0.2^{*}$ \\
$\mathbf{3 x - 7}$ & $1.0^{*}$ & 0.7 & 22.0 & 0.4 & 7.8 & 4.1 & 1.3 \\
$\mathbf{3 x - 8}$ & 2.7 & 0.7 & 11.5 & 1.7 & $1.2^{*}$ & 2.0 & 0.8 \\
$\mathbf{3 x - 9}$ & 1.0 & --- & 3.7 & 1.1 & $0.8^{*}$ & $1.1^{*}$ & 0.8 \\
$\mathbf{3 x - 1 0}$ & 2.3 & --- & 2.0 & 1.0 & 1.9 & 4.1 & 0.2 \\
$\mathbf{3 x - 1 1}$ & 1.6 & --- & --- & $0.2^{*}$ & 1.0 & 0.9 & 0.3 \\
$\mathbf{3 x - 1 2}$ & 1.5 & --- & --- & 0.8 & --- & 1.1 & 0.0 \\
$\mathbf{3 x - 1 3}$ & 0.9 & --- & --- & --- & --- & 0.4 & --- \\
$\mathbf{3 x - 1 4}$ & 0.2 & --- & --- & --- & --- & -- & -- \\
\hline * Conformers that have proper geometries to form CF $\cdots$ CO interactions. & & &
\end{tabular}

We have shown in a previous work that it is rare to find organic bound $\mathrm{F}$ atoms participating in 5-membered intramolecular ring contacts in organofluorine compounds. ${ }^{[16]}$ Thus, it is not surprising that 5-membered ring formation upon $\mathrm{CF} \cdots \mathrm{C}=\mathrm{O}$ interactions appear to be equally rare. In order to evaluate CF...CO interactions in a less rigid ring, we extended the present work to aliphatic fluorinated carbonylic compounds which could form 6-membered rings upon formation of CF …CO interactions (Scheme 1).

Because of the increased degree of freedom in the longer alkyl chain, many more conformers are found for derivatives 4a-4f (up to 39 each have been located in our Monte-Carlo based technique). Relative energies, enthalpies and Gibbs free energies are given in Tables S17-S23 in the ESI, populations based on free energies are collected in Table 3. Populations of conformers that may form $\mathrm{CF} \cdots \mathrm{C}=\mathrm{O}$ interactions in compounds $\mathbf{4 a - 4 f}$ (marked with an asterisk in Table 3) range from $0.0 \%$ to $5.4 \%$ when Gibbs free energies are considered, i.e. they have little influence on the overall conformational profile. Thus, although $\mathrm{CF} \cdots \mathrm{C}=\mathrm{O}$ interactions may be stabilising in the studied compounds (e.g. such conformers are the global minimum, or isoenergetic with it, for $4 \mathbf{a}$ and $\mathbf{4 f}$, see Tables S17 and S23, respectively), the extent of the stabilisation is not sufficient to overcome the entropic penalty associated with such six-memberd cyclic structures. In terms of free energies, extended conformers without $\mathrm{CF} \cdots \mathrm{C}=\mathrm{O}$ interactions tend to be 
preferred. Solvation is unlikely to change this situation for the compounds under scrutiny.

Conformers with intramolecular $\mathrm{CF} \cdots \mathrm{CO}$ interactions tend to have slightly higher dipole moments than the extended global minima, however immersion in a polar continuum does not indicate that there is sufficient additional stabilisation to increase the population of the CF $\cdots \mathrm{CO}$ conformers (results not shown).

Table 3: Calculated populations of conformers of compounds $\mathbf{4 a - 4 g}$ obtained at the B3LYPD3/aug-cc-pVDZ theoretical level. Populations shown refer to Gibbs free energies $\Delta G$.

\begin{tabular}{|c|c|c|c|c|c|c|c|c|c|c|c|c|c|c|c|}
\hline & $4 a$ & $4 b$ & $4 c$ & 4d & $4 e$ & $4 \mathbf{f}$ & $4 \mathrm{~g}$ & & $\mathbf{4 a}$ & $4 b$ & $4 c$ & 4d & $4 e$ & 4f & $4 g$ \\
\hline $4 x-1$ & 17.2 & $5.4^{*}$ & $1.3^{*}$ & 21.5 & 18.3 & $1.8^{*}$ & $1.8^{*}$ & $4 x-21$ & 1.5 & 1.2 & 1.6 & 1.0 & 0.7 & $0.0 *$ & $0.0^{*}$ \\
\hline $4 x-2$ & $1.9 *$ & 7.6 & 14.9 & 5.5 & 7.7 & 8.4 & 8.4 & $4 x-22$ & 0.3 & 3.5 & 1.5 & 1.3 & 0.2 & 0.3 & 0.3 \\
\hline $4 x-3$ & 7.3 & 17.2 & 4.0 & $3.0 *$ & 7.6 & 20.0 & 20.0 & $4 x-23$ & 1.3 & 0.4 & 1.2 & 0.4 & 0.7 & 0.3 & 0.3 \\
\hline $4 x-4$ & 6.2 & 9.2 & 5.4 & 6.1 & $1.3^{*}$ & 10.3 & 10.3 & $4 x-24$ & 1.0 & 0.4 & 1.3 & 1.4 & 1.0 & 0.2 & 0.2 \\
\hline $4 x-5$ & 10.0 & 9.4 & 9.2 & 5.5 & 9.2 & 14.7 & 14.7 & $4 x-25$ & 0.9 & 0.5 & 1.4 & 0.4 & 0.7 & 0.8 & 0.8 \\
\hline $4 x-6$ & 3.7 & 2.0 & 3.3 & 1.7 & 4.9 & 6.1 & 6.1 & $4 x-26$ & 1.2 & 0.3 & 1.1 & 0.7 & $0.7 *$ & 0.2 & 0.2 \\
\hline $4 x-7$ & 7.5 & 3.3 & 5.8 & 2.1 & 6.5 & 6.5 & 6.5 & $4 x-27$ & 0.4 & 0.4 & 0.3 & 0.1 & 1.2 & 0.0 & 0.0 \\
\hline $4 x-8$ & 5.6 & 5.6 & 4.7 & 9.3 & 5.5 & 3.6 & 3.6 & $4 x-28$ & 0.6 & $0.0^{*}$ & $0.1^{*}$ & 0.4 & 0.8 & 0.0 & 0.0 \\
\hline $4 x-9$ & 4.3 & 5.5 & 7.5 & 12.6 & 1.3 & 3.9 & 3.9 & $4 x-29$ & $0.1^{*}$ & 0.2 & 0.4 & $0.0 *$ & 0.6 & $0.2 *$ & 0.2 \\
\hline $4 x-10$ & 3.6 & 3.5 & 3.1 & 3.1 & 5.4 & 4.9 & 4.9 & $4 x-30$ & 0.4 & 0.2 & 0.8 & 0.4 & 0.3 & 6.2 & 6.2 \\
\hline $4 x-11$ & 4.0 & 2.0 & 5.0 & 1.0 & 1.2 & 1.0 & 1.0 & $4 x-31$ & 0.1 & 0.1 & 0.5 & 0.4 & 1.1 & 0.1 & 0.1 \\
\hline $4 x-12$ & 4.1 & 0.4 & 3.9 & 4.0 & 3.1 & 0.9 & 0.9 & $4 x-32$ & 0.4 & --- & --- & 0.3 & 3.1 & 0.1 & 0.1 \\
\hline $4 x-13$ & 4.1 & 1.5 & 2.9 & 3.2 & $0.1^{*}$ & $0.5^{*}$ & 0.5 & $4 x-33$ & 0.3 & --- & --- & --- & 0.3 & 0.1 & 0.1 \\
\hline $4 x-14$ & 2.7 & 2.0 & 7.7 & 1.5 & 3.9 & 0.9 & 0.9 & $4 x-34$ & 0.2 & --- & --- & --- & 0.2 & 4.5 & 4.5 \\
\hline $4 x-15$ & 1.2 & 1.7 & 2.7 & 1.8 & 2.0 & 0.5 & 0.5 & $4 x-35$ & 0.2 & --- & --- & --- & 0.3 & 0.0 & 0.0 \\
\hline $4 x-16$ & 2.0 & 1.9 & $0.6^{*}$ & 3.1 & 2.0 & 0.5 & 0.5 & $4 x-36$ & 0.2 & --- & --- & --- & 0.3 & --- & 0.0 \\
\hline $4 x-17$ & 1.5 & 2.5 & 1.7 & 2.6 & 2.9 & 0.2 & 0.2 & $4 x-37$ & 1.1 & --- & --- & --- & 0.1 & --- & 0.3 \\
\hline $4 x-18$ & 0.7 & 2.0 & 4.8 & 2.1 & 2.5 & 1.4 & 1.4 & $4 x-38$ & 0.0 & --- & --- & --- & 0.1 & --- & 0.3 \\
\hline $4 x-19$ & 1.0 & 9.2 & $0.1 *$ & 2.3 & 1.3 & 0.7 & 0.7 & $4 x-39$ & --- & --- & --- & --- & 0.1 & --- & 0.2 \\
\hline $4 x-20$ & 1.1 & 0.8 & 1.4 & 1.1 & 0.7 & 0.1 & 0.1 & & & & & & & & \\
\hline
\end{tabular}

\section{Conclusions}

The present work reports the study of $\mathrm{C}^{\delta+} \mathrm{F}^{\delta-} \cdots \mathrm{C}^{\delta+} \mathrm{O}^{\delta-}$ interactions in four different set of compounds using theoretical calculations. The first set (1) is composed of compounds that may form intermolecular $\mathrm{CH}_{3} \mathrm{~F} \cdots \mathrm{C}=\mathrm{O}$ interactions. According to calculations at the B3LYP-D3/augcc-pVDZ and MP2/aug-cc-pVTZ//MP2/aug-cc-pVDZ theoretical levels, these $\mathrm{CH}_{3} \mathrm{~F} \cdots \mathrm{C}=\mathrm{O}$ interactions may be stabilising by ca. $1 \mathrm{kcal} \mathrm{mol}^{-1}$ when the carbonyl is incorporated into common functional groups such as aldehydes, ketones, esters, amides and acyl chlorides and when the $\mathrm{CH}_{3} \mathrm{~F}$ group approaches the carbonyl groups in a quasi-perpendicular fashion (with $\mathrm{C} \cdots \mathrm{C}=\mathrm{O}$ angles in the range of $\left.\sim 81-102^{\circ}\right)$. B3LYP calculations without DFT-D3 dispersion 
corrections do not predict significant $\mathrm{CF} \cdots \mathrm{C}=\mathrm{O}$ interaction energies, indicating the importance of dispersion for modelling this type of interaction.

Compounds of sets 2-4 may form intramolecular $\mathrm{CF} \cdots \mathrm{C}=\mathrm{O}$ stabilising interactions. However, such interactions turn out to be of negligible importance in determining the conformational preferences of these sets of compounds. For sets $\mathbf{3}$ and $\mathbf{4}$ with their linear alkyl chains, such interactions serve to stabilise some folded conformers to the extent that they are among the most stable structures or even the global minimum on the potential energy surface; however, the interaction is not enough to overcome the entropic penalty associated with achieving cyclic structures, and extended conformers without $\mathrm{CF} \cdots \mathrm{C}=\mathrm{O}$ contacts tend to be populated most. "Through space" $J(\mathrm{~F}, \mathrm{C})$ SSCCs were calculated to be very small for all sets of compounds 1-4 and insensitive to the F...C distance, and are thus of little practical use as a direct probe for observing $\mathrm{CF} \cdots \mathrm{C}=\mathrm{O}$ interactions. This contrasts to couplings across hydrogen bonds, which are frequently used in the literature to detect such interactions to fluorine. It is already recognised that these weak $\mathrm{CF} \cdots \mathrm{C}=\mathrm{O}$ interactions can refine binding interactions of ligands to peptides, however the current study suggests that it will be difficult to design a simple organic framework where they would emerge as a decisive and detectable structure-forming force.

Acknowledgements. We thank EaStCHEM, CNPq and FAPESP for the studentship (to R.A.C. \#2011/01170-1, FAPESP), as is CNPq for the fellowship (R.R.).

\section{References}

[1] Ojima, I. Fluorine in medicinal chemistry and chemical biology, John Wiley \& Son, Chichester, 2009.

[2] W. K. Hagmann, J. Med. Chem. 2008, 51, 4359.

[3] G. Sandford, Phil. Trans. R. Soc. Lond. 2000, 358, 455. 
[4] See the van der Waals radii of $1.20 \AA$ and $1.47 \AA$ for $\mathrm{H}$ and $\mathrm{F}$, respectively (A. Bondi, $J$. Phys. Chem. 1964, 68, 441-451) and the mean C-H and C-F bond lengths of $1.09 \AA$ and $1.35 \AA$, respectively (D. O'Hagan, Chem. Soc. Rev. 2008, 37, 308).

[5] A. Harsanyi, G. Sandford, Green Chem. 2015 (In Press) DOI: 10.1039/C4GC02166E

[6] S. Dall'Angeloa, N. Bandaranayaka, A. D. Windhorstc, D. J. Vugtsc, D. van der Bornc, M. Onega, L. F. Schweiger, M. Zanda, D. O'Hagan, Nucl. Med. Bio. 2013, 40, 464.

[7] P. Kirsch, Modern Fluoroorganic Chemistry: Synthesis, Reactivity, Applications, WileyVCH, Weinheim, 2004.

[8] B. K. Park, N. R. Kitteringham, P. M. O’Neill Annu. Rev. Pharmacol. Toxicol. 2001, 41, 443.

[9] L. Pauling, The Nature of the Chemical Bond and the Structure of Molecules and Crystals: An Introduction to Modern Structural Chemistry, Cornell University Press, Ithaca, NY, 1939.

[10] P. Shah, A. D. Westwell, J. Enz. Inhib. Med. Chem. 2007, 22, 527.

[11] L. Hunter, Beilstein J. Org. Chem. 2010, 6, No. 38.

[12] J. D. Dunitz, R. Taylor, Chem. Eur. J. 1997, 3, 89.

[13] J. Graton, Z. Wang, A. M. Brossard, D. G. Monteiro, J. Y. Le Questel, B. Linclau, Angew. Chem. Int. Ed. Engl. 2012, 51, 6176.

[14] P. A. Champagne, J. Desroches, J.-F. Paquin, Synthesis 2015, 47, 306.

[15] R. A. Cormanich, M. A. Moreira, M. P. Freitas, T. C. Ramalho, C. P. A. Anconi, R. Rittner, R. H. Contreras, C. F. Tormena, Magn. Reson. Chem. 2011, 12, 763.

[16] R. A. Cormanich, M. P. Freitas, C. F. Tormena, R. Rittner, RSC Advances 2012, 2, 4169.

[17] R. A. Cormanich, R. Rittner, M. P. Freitas, M. Bühl Phys. Chem. Chem. Phys. 2014, 16, 19212.

[18] K. Reichenbächer, H. I. Süss, J. Hulliger, Chem. Soc. Rev. 2005, 34, 22.

[19] T. V. Rybalova, I. Y. Bagryanskaya, J. Struct. Chem. 2009, 50, 741.

[20] R. A. Cormanich, R. Rittner, D. O’Hagan, M. Bühl, J. Phys. Chem. A 2014, 118, 7901.

[21] D. Y. Buissonneaud, T. van Mourik, D. O'Hagan, Tetrahedron, 2010, 66, 2196.

[22] F. H. Allen, Acta Cryst. 2002, 58, 380.

[23] H. M. Berman, J. Westbrook, Z. Feng, G. Gilliland, T. N. Bhat, H. Weissig, I. N. Shindyalov, P. E. Bourne, Nucleic Acids Res. 2000, 28, 235.

[24] J. A. Olsen, D. W. Banner, P. Seiler, U. O. Sander, A. D'Arcy, M. Stihle, K. Müller, F. Diederich, Angew. Chem. Int. Ed. 2003, 42, 2507.

[25] K. Müller, C. Faeh, F. Diederich Science 2007, 317, 1881.

[26] F. Hof, D. M. Scofield, W. B. Schweizer, F. Diederich, Angew. Chem. Int. Ed. 2004, 43, 5056. 
[27] J. A. Olsen, D. W. Banner, P. Seiler, B. Wagner, T. Tschopp, U. Obst-Sander, M. Kansy, K. Müller, F. Diederich, Chem. Bio. Chem. 2004, 5, 666.

[28] Gaussian 09, Revision D.01, M. J. Frisch, G. W. Trucks, H. B. Schlegel, G. E. Scuseria, M. A. Robb, J. R. Cheeseman, G. Scalmani, V. Barone, B. Mennucci, G. A. Petersson, H. Nakatsuji, M. Caricato, X. Li, H. P. Hratchian, A. F. Izmaylov, J. Bloino, G. Zheng, J. L. Sonnenberg, M. Hada, M. Ehara, K. Toyota, R. Fukuda, J. Hasegawa, M. Ishida, T. Nakajima, Y. Honda, O. Kitao, H. Nakai, T. Vreven, J. A. Montgomery, Jr., J. E. Peralta, F. Ogliaro, M. Bearpark, J. J. Heyd, E. Brothers, K. N. Kudin, V. N. Staroverov, R. Kobayashi, J. Normand, K. Raghavachari, A. Rendell, J. C. Burant, S. S. Iyengar, J. Tomasi, M. Cossi, N. Rega, J. M. Millam, M. Klene, J. E. Knox, J. B. Cross, V. Bakken, C. Adamo, J. Jaramillo, R. Gomperts, R. E. Stratmann, O. Yazyev, A. J. Austin, R. Cammi, C. Pomelli, J. W. Ochterski, R. L. Martin, K. Morokuma, V. G. Zakrzewski, G. A. Voth, P. Salvador, J. J. Dannenberg, S. Dapprich, A. D. Daniels, Ö. Farkas, J. B. Foresman, J. V. Ortiz, J. Cioslowski, and D. J. Fox, Gaussian, Inc., Wallingford CT, 2009.

[29] A. D. Becke J. Chem. Phys. 1993, 98, 5648.

[30] C. Lee, W. Yang, R. G. Parr, Phys. Rev. B 1988, 37, 785.

[31] S. Grimme, J. Antony, S. Ehrlich, S. Krieg, J. Chem. Phys. 2010, 132, 154104.

[32] S. F. Boys, F. Bernardi, Mol. Phys. 1970, 19, 553.

[33] S. Simon, M. Duran, J. J. Dannenberg, J. Chem. Phys. 1996, 105, 11024.

[34] T. A. Keith, AIMAll (Version 14.11.23), TK Gristmill Software, Overland Park KS, USA, 2014 (aim.tkgristmill.com).

[35] A. D. Becke, J. Chem. Phys. 1993, 98, 1372.

[36] V. Barone, in Recent Advances in Density Functional Methods, Part I, D. P.Chong, World Scientific Publ. Co., Singapore, 1996.

[37] F. Nozirov, T. Kupka, M. J. Stachów, Chem. Phys. 2014, 140, 144303.

[38] R. Suardíaz, C. Pérez, R. Crespo-Otero, J. M. García de la Vega, J. San Fabián, J. Chem. Theor. Comput. 2008, 4, 448.

[39] Y. Shao, L. F. Molnar, Y. Jung, J. Kussmann, C. Ochsenfeld, S. T. Brown, A. T. B. Gilbert, L. V. Slipchenko, S. V. Levchenko, D. P. O’Neill, R. A. DiStasio Jr., R. C. Lochan, T. Wang, G. J. O. Beran, N. A. Besley, J. M. Herbert, C. Y. Lin, T. Van Voorhis, S. H. Chien, A. Sodt, R. P. Steele, V. A. Rassolov, P. E. Maslen, P. P. Korambath, R. D. Adamson, B. Austin, J. Baker, E. F. C. Byrd, H. Dachsel, R. J. Doerksen, A. Dreuw, B. D. Dunietz, A. D. Dutoi, T. R. Furlani, S. R. Gwaltney, A. Heyden, S. Hirata, C-P. Hsu, G. Kedziora, R. Z. Khalliulin, P. Klunzinger, A. M. Lee, M. S. Lee, W. Z. Liang, I. Lotan, N. Nair, B. Peters, E. I. Proynov, P. A. Pieniazek, Y. M. Rhee, J. Ritchie, E. Rosta, C. D. Sherrill, A. C. Simmonett, J. E. Subotnik, H. L. Woodcock III, W. Zhang, A. T. Bell, A. K. Chakraborty, D. M. Chipman, F. J. Keil, A. Warshel, W. J. Hehre, H. F. Schaefer, J. Kong, A. I. Krylov, P. M. W. Gill, M. Head-Gordon, Phys. Chem. Chem. Phys., 2006, 8, 3172.

[40] A. E. Reed, L. A. Curtiss, F. Weinhold, Chem. Rev.,1988, 88, 889.

[41] E. Johnson, S. Keinan, P. Mori-Sánchez, J. Contreras-García, A. Cohen, W. Yang, J. Am. Chem. Soc. 2010, 132, 6498. 
[42] For simplicity a near-linear C-F...C arrangement has been imposed in the partial optimisations, despite the more pronounced variability of this parameter in the solid (cf. reference [23].

[43] I. Alkorta, J. E. Elguero, H. H. Limbach, I. G. Shenderovich, T. Winkler, Magn. Reson. Chem. 2009, 47, 585

[44] D. Asturiol, M. Duran, P. Salvador, J. Chem. Phys. 2008, 128, 144108.

[45] "Normal" steric repulsion disfavours bis(axial) 1,3-cyclohexane derivatives relative to the bis(equatorial) conformers by $1.3 \mathrm{kcal} / \mathrm{mol}$ (1,3-difluoro) to $5.0 \mathrm{kcal} / \mathrm{mol}$ (1,3-dimethyl species, $\Delta \mathrm{E}$ values at B3LYP-D3/aug-cc-pVDZ); indeed stronger transannular interactions between axial substituents appear to be needed to reverse this conformational preference.

[46] For some constrained cage systems, ${ }^{4} J(\mathrm{C}, \mathrm{F})$ couplings exceeding $20 \mathrm{~Hz}$ have been reported, see e.g.: R. H. Contreras, A. L. Esteban, E. Diez, N. J. Head, E. J. Della, Mol. Phys. 2006, 104, 485 .

[47] Of course, conformations of cyclohexane derivatives can be inferred from ${ }^{3} J(H, H)$ couplings if all ${ }^{1} \mathrm{H}$ resonances can be fully assigned, but this is beyond the scope of the present analysis. 